\title{
SERUM INTERLEUKIN-18 AS A NOVEL BIOMARKER FOR DISEASE ACTIVITY OF SYSTEMIC LUPUS ERYTHEMATOSUS PATIENTS
}

By

AMAL S. ELSHAL ${ }^{1}$, MOHAMED H. SHERIF ${ }^{2}$, AMAL B. ABDULSATTAR ${ }^{3}$

AND FATMA ELZAHRAA E. GOUDA ${ }^{*}$

Department of Medical Biochemistry ${ }^{1}$, Faculty of Medicine, Zagazig University, Department of Chemistry ${ }^{2}$, Faculty of Science, Zagazig University and Department of Rheumatology and Rehabilitation ${ }^{3}$, Faculty of Medicine,

Zagazig University ( ${ }^{\star}$ Correspondence: Fegouda@zu.edu.eg)

\section{Abstract}

Interleukin-18 (IL-18) is a vital cytokine, which mediated organ failure and elevated in autoimmune disorders as Systemic Lupus Erythematosus. This study investigated the importance role of IL-18 as a diagnostic marker for disease activity of systemic lupus erythematosus (SLE) and development of lupus nephritis (LN). This cross-sectional study was carried out on 41 SLE patients with LN, 31 lupus non-nephritis patients and 20 healthy controls. The IL-18 serum levels were measured by IL-18 ELISA kit, to evaluate the activity of Systemic Lupus Erythematosus Disease Activity Index (SLEDAI) score. The results showed significant increase in serum IL-18 level in patients with LN $(174.09 \pm 33.19)$ than both lupus non nephritis patients $(9139.45 \pm 64.39)$ and healthy control $(46.06 \pm 16.42)$, with significant correlation between IL-18 level and SLEDAI.

Keywords: Interleukin-18, Systemic lupus erythematosus, disease activity, Lupus nephritis.

\section{Introduction}

Autoimmune diseases as systemic lupus erythematosus (SLE) distinguish by autoantibodies generation, polyclonal $\mathrm{T}$ activation and B-lymphocytes and formation of immune complexes causing tissue and organ damage (Kaplanski, 2018). The common complication of SLE is Lupus nephritis (LN) which impacts numerous of patients. Up to half of SLE patients develop LN so renal failure is a risk factor for death during the disease course (Park et al, 2007; Dinarello, 2007). Kidney damage of LN induced fundamentally by unusual generation of cytokines and chemokines (Liu et al, 2012). Deposition of cytokine in kidney mediates inflammation by stimulation number of inflammatory reactions causing tissue hurt by the immune complexes (Tucci et al, 2008; Avihingsanon and Hirankarn, 2010). IL-18 is a proinflammatory cytokine isolated in 1995 as a co-factor that triggers production of Th1 cells to gamma interferon (INF- $\gamma$ ) (Harrison et al, 2015). The IL-18 secreted by macrophages Kupffer cells, keratinocytes and other antigen-presenting cells mediated ischemic injury in kidney, brain, heart nervous system, serous membranes and/or others (Fessler and Boumpas, 1995). The IL-18 associated with numerous inflammatory diseases including infections, autoimmune diseases, rheumatoid arthritis, cancer, metabolic syndrome and atherosclerosis activates natural killer cell and stimulates the production of Th2 cytokines (Beker et al, 2018). IL-18 expression in glomerular intercalated cells of late distal convoluted tubule, connecting tubule, \& collecting duct causing LN (Chen et al, 2009; Boraschi and Dinarello, 2006).

\section{Patients and Methods}

Seventy two patients affected with SLE, as diagnosed according to the 1982 American College of Rheumatology (ACR) revised classification criteria for SLE, modified in 1997 were consecutively recruited from in and outpatient clinic of Rheumatology and Rehabilitation Department, Zagazig University Hospitals, in this cross sectional study from May 2017 to February 2018. The Regional Ethics Committee of Zagazig University Hospitals approved the study and written informed consent was individually obtained. Those with age below18, diabetes mellitus, uncontrolled hypertension, overlap syndrome, malignancy, or chronic infections were excluded.

The study reviewed these patients' medical 
records (socio-demographic, age, sex, marital status, residency, occupation, educational level, socioeconomic status), the past medical history with disease duration, and comorbidities were recorded. Disease activity was performed by rheumatologist using the SLE Disease Activity Index (SLEDAI) (Bombardier et al, 1992).

Blood and urine samples were collected. Serum was isolated and stored at $-80^{\circ} \mathrm{C}$ for the biochemical analysis: full blood picture (CBC), ESR, CRP, serum creatinine, ALT, AST, C3, C4, ANA, and anti-dsDNA and complete urine analysis and estimation of $24 \mathrm{hrs}$ urinary protein were done. The serum IL-18 was measured by Bioneovan Human IL-18 ELISA kit (No. 18, Keyuan Road, DaXing Industry Zone, Beijing, China). According to the renal involvement; the SLE patients were divided into two groups: GI: 31 SLE patients with no renal involvement (lupus non-nephritis), and GII: 41 SLE patients with renal involvement (lupus nephritis) LN. Lupus nephritis patients were de- fined by the persistent proteinuria $>0.5 \mathrm{~g} /$ 24h, hematuria and cellular casts (Lit et al, 2006). GIII: 20 ages and sex matched apparently the healthy persons who served as control group.

Statistical analysis: Data were analyzed by SPSS 14.0 version using one way analysis of variance (ANOVA) according to Levesque (2007). Numerical data were expressed as mean $\pm \mathrm{SD}, \mathrm{P}$ values $<0.05$ were considered significant. Pearson correlation co-efficiency test was used to test association between variables. $\mathrm{P}$ was significant if $<0.05$ at confidence interval of $95 \%$.

\section{Results}

The SLE patients without LN ages ranged from (19-49) years with a mean of 26.93 \pm 7.28. The SLE patients with LN ages ranged

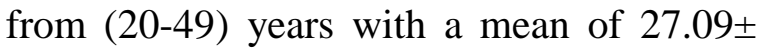
7.76. The control group ages ranged from (20-50) years with a mean of 26.14 \pm 5.85 years. There was no significant difference between groups in age or sex (Tab. 1).

Table 1: Demographic and clinical data of patients group.

\begin{tabular}{|c|c|c|c|}
\hline Variable & SLE Patients without LN & SLE Patients with LN & $\mathrm{P}$ \\
\hline Age (yrs) mean \pm SD & $26.93 \pm .28$ & $27.09 \pm 7.76$ & 0.21 \\
\hline Female (n \%) & $28(90.32 \%)$ & $38(92.68 \%)$ & 0.20 \\
\hline Duration of disease, $y($ mean \pm SD) & $4.67 \pm 1.18$ & $3.75 \pm 1.28$ & 0.24 \\
\hline Fatigue $(\mathrm{n} \%)$ & $11(35.48 \%)$ & $14(34.14 \%)$ & 0.22 \\
\hline Arthralgia (n \%) & $8(25.80 \%)$ & $14(34.14 \%)$ & 0.26 \\
\hline Myalgia (n \%) & $4(12.90 \%)$ & $4(9.75 \%)$ & 0.23 \\
\hline Photo sensitivity (n \%) & $8(25.80 \%)$ & $9(21.95 \%)$ & 0.21 \\
\hline Discoid rash $(\mathrm{n} \%)$ & $3(9.67 \%)$ & $3(7.31 \%)$ & 0.28 \\
\hline Raynaud's ph. (n \%) & $7(22.58 \%)$ & $12(29.26 \%)$ & 0.25 \\
\hline Neuropsychiatric manifestations & $14(45.16 \%)$ & $16(39.02 \%)$ & 0.10 \\
\hline Arthritis (n \%) & $23(74.19 \%)$ & $22(53.65 \%)$ & 0.12 \\
\hline Myositis (n \%) & $0(0 \%)$ & $0(0 \%)$ & \\
\hline Malar Rash (n \%) & $31(100 \%)$ & $41(100 \%)$ & $0.001 * *$ \\
\hline Alopecia (n \%) & $28(90.32 \%)$ & $21(51.21 \%)$ & 0.16 \\
\hline Mucous membrane (ulcers) (n \%) & $10(32.25 \%)$ & $12(29.26 \%)$ & 0.24 \\
\hline Pleurisy $(\mathrm{n} \%)$ & $7(22.58 \%)$ & $5(12.19 \%)$ & 0.27 \\
\hline Pericarditis (n \%) & $3(9.67 \%)$ & $3(7.31 \%)$ & 0.39 \\
\hline SLEDAI score (mean \pm SD) & $13.02 \pm 6.21$ & $14.79 \pm 6.78$ & $0.05^{*}$ \\
\hline Mild activity 1-5 (n \%) & $11(35.48 \%)$ & $14(34.14 \%)$ & 0.22 \\
\hline Moderate activity 6-10 (n \%) & $8(25.80 \%)$ & $10(24.39 \%)$ & 0.24 \\
\hline High activity 11-19 (n \%) & $2(6.45 \%)$ & $5(12.19 \%)$ & 0.38 \\
\hline Very high activity $\geq 20 \quad(\mathrm{n} \%)$ & $9(29.03 \%)$ & $11(26.82 \%)$ & 0.41 \\
\hline
\end{tabular}

The most predominant clinical variable was malar rash followed by alopecia then arthritis while the least ones were the pericarditis and vasculitis followed by purpura. 
None of the patient had organic brain syndrome, visual disturbance, cerebrovascular accident, myositis or cranial nerve affection.

SLEDAI of the SLE patients ranged from 0 to 31 for SLE patients without LN and 0 to
39 for LN patients. The frequencies of mild, moderate, high, very high activity were categories, while the inactive category was detected in the SLE patients. The majority had mild disease activity (Tab. 1).

Table 2: Laboratory investigation of groups.

\begin{tabular}{|c|c|c|c|}
\hline Variable & $\begin{array}{l}\text { SLE Patients without } \\
\text { LN }\end{array}$ & $\begin{array}{l}\text { SLE Patients with } \\
\text { LN }\end{array}$ & $\mathrm{P}$ value \\
\hline 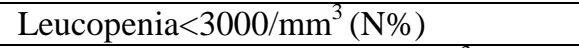 & $10(3.22 \%)$ & $8(19.51 \%)$ & 0.31 \\
\hline Thrombocytopenia< $100000 / \mathrm{mm}^{3}(\mathrm{~N} \%)$ & $6(19.35 \%)$ & $7(17.07 \%)$ & 0.48 \\
\hline ESR level mm/hr $\left(1^{\text {st }}\right.$ hour $(\mathrm{M} \pm \mathrm{SD})$ & $41.36 \pm 23.18$ & $43.40 \pm 19.91$ & 0.56 \\
\hline CRP level $(\mathrm{M} \pm \mathrm{SD})$ & $9.56 \pm 17.70$ & $9.99 \pm 14.93$ & 0.46 \\
\hline $\operatorname{Albumin}(\mathrm{g} / \mathrm{dl})(\mathrm{M} \pm \mathrm{SD})$ & $3.30 \pm 0.53$ & $3.32 \pm 0.49$ & 0.62 \\
\hline $\operatorname{ALT}(\mu / \mathrm{L})(\mathrm{M} \pm \mathrm{SD})$ & $24.78 \pm 7.96$ & $25.13 \pm 6.74$ & 0.52 \\
\hline $\operatorname{AST}(\mu / \mathrm{L})(\mathrm{M} \pm \mathrm{SD})$ & $31.47 \pm 13.40$ & $32.35 \pm 11.36$ & 0.56 \\
\hline Blood Urea (mg/dl) $(\mathrm{M} \pm \mathrm{SD})$ & $18.06 \pm 7.03$ & $19.50 \pm 9.32$ & 0.23 \\
\hline Serum creatinine $(\mathrm{mg} / \mathrm{dl})(\mathrm{M} \pm \mathrm{SD})$ & $1.26 \pm 0.86$ & $1.35 \pm 0.92$ & $0.001 * *$ \\
\hline Creatinine clearance $(\mathrm{ml} / \mathrm{min}).(\mathrm{M} \pm \mathrm{SD})$ & $106.52 \pm 46.15$ & $110.22 \pm 34.7$ & $0.0001 * *$ \\
\hline Pyuria: (>5WBCs/HPF) (N\%) & $13(41.93 \%)$ & $30(73.17 \%)$ & 0.21 \\
\hline Hematuria: (>5RBCs/HPF) (N\%) & $12(38.70 \%)$ & $17(71.46 \%)$ & 0.14 \\
\hline Casts (N\%) & $8(25.80 \%)$ & $14(34.14 \%)$ & 0.11 \\
\hline $\begin{array}{l}\text { Proteinuria: }>500 \mathrm{mg} / 24 \mathrm{hrs} \text { urine. }(\mathrm{N} \%) \\
(\mathrm{M} \pm \mathrm{SD})\end{array}$ & $\begin{array}{l}16(51.61 \%) \\
(575.5 \pm 4.73)\end{array}$ & $\begin{array}{l}22(53.65 \%) \\
(819.67 \pm 5.95)\end{array}$ & $0.001 * *$ \\
\hline $\mathrm{ANA}(\mathrm{M} \pm \mathrm{SD})$ & $57.72 \pm 14.27$ & $62.72 \pm 29.39$ & 0.16 \\
\hline Anti-dsDNA(M \pm SD) & $36.30 \pm 13.74$ & $47.25 \pm 12.62$ & 0.14 \\
\hline $\mathrm{C} 3$ level $(\mathrm{M} \pm \mathrm{SD})$ & $67.57 \pm 34.06$ & $55.84 \pm 20.59$ & 0.12 \\
\hline $\mathrm{C} 4$ level$(\mathrm{M} \pm \mathrm{SD})$ & $21.03 \pm 5.93$ & $19.19 \pm 3.43$ & 0.13 \\
\hline IL-18(M+SD) & $139.45 \pm 64.39$ & $174.09 \pm 33.19$ & $0.0001 * *$ \\
\hline
\end{tabular}

Abnormalities in the blood picture were evident with leucopenia $<3000 / \mathrm{mm}^{3}$ found in $(3.22 \%)$ SLE patients without LN and $(19.51 \%)$ in SLE patients with LN, thrombocytopenia $<100,000 / \mathrm{mm}^{3}(19.35 \%)$ was found in the SLE patients without LN and $(17.07 \%)$ in the SLE patients with LN.

The kidney functions and urine analysis abnormalities where the most predominant result, was proteinuria (> 500mg/day) found in $(51.61 \%)$ SLE patients without LN, (53.65\%) SLE patients with LN then pyuria in $(41.93 \%)$ SLE patients without LN, (73.17\%) SLE patients with LN; hematuria in $(38.7 \%)$ patients, $(41.46 \%) \mathrm{LN}$ patients but casts was found only in (25.8\%) SLE patients without LN, but $(34.14 \%)$ were in SLE patients with LN. ANA was positive in all patients, while anti-dsDNA was $(64.51 \%)$ positive in SLE patients without LN, and $(65.85 \%)$ in SLE patients with LN. Low C3 level was $(45.16 \%)$ in SLE patients without LN and (48.78\%) SLE patients with LN, while low C4 level was found in $(25.80 \%)$ SLE in $(56.09 \%)$ LN patients.

The serum level of IL-18 was significantly higher in patients with LN than in SLE ones without LN where it was found (139.45

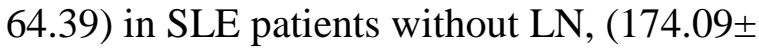
33.19)ng/dl in SLE patients with $\mathrm{LN}$ and from $(46.06 \pm 16.42) \mathrm{ng} / \mathrm{dl}$ in control group (Tab. 2). 
Table 3: Correlation between serum IL-18 levels and other parameters.

\begin{tabular}{|c|c|c|c|}
\hline Variable & Pearson-Correlation & $\mathrm{R}$ & Sig.(2taild) P value \\
\hline Age & 0.28 & & 0.08 \\
\hline Duration of disease & 0.02 & & 0.90 \\
\hline Fatigue & 0.09 & & 0.93 \\
\hline Arthralgia & 0.10 & & 0.28 \\
\hline Myalgia & 0.39 & & 0.56 \\
\hline Photo sensitivity & 0.11 & & 0.14 \\
\hline Discoid rash & 0.14 & & 0.67 \\
\hline Purpura & 0.04 & & 0.81 \\
\hline Raynaud's ph. & 0.12 & & 0.47 \\
\hline DVT & 0.04 & & 0.15 \\
\hline Vasculitis & $0.26 *$ & & $0.02 *$ \\
\hline Arthritis & $0.34 * *$ & & $0.04 *$ \\
\hline Myositis & 0.14 & & 0.14 \\
\hline Malar Rash & 0.45 & & 0.67 \\
\hline Alopecia & 0.15 & & 0.88 \\
\hline Mucous membrane & 0.05 & & 0.31 \\
\hline Pleurisy & 0.07 & & 0.49 \\
\hline Pericarditis & 0.14 & & 0.11 \\
\hline Fever & 0.02 & & 0.14 \\
\hline Neuropsychiatric manifestation & $0.33 * *$ & & $0.05 *$ \\
\hline SLEDAI score & $0.42 * *$ & & $0.0001 * *$ \\
\hline Leucopenia & $0.29 *$ & & $0.05 *$ \\
\hline Thrombocytopenia & $-0.31 *$ & & $0.002 * *$ \\
\hline ESR & 0.32 & & $0.001 * *$ \\
\hline CRP & 0.24 & & $0.003 * *$ \\
\hline Albumin & $-0.21 *$ & & 0.36 \\
\hline ALT & 0.18 & & 0.06 \\
\hline AST & 0.19 & & 0.10 \\
\hline Urea & 0.14 & & 0.17 \\
\hline creatinine & $0.32 * *$ & & $0.002 * *$ \\
\hline Creatinine clearance & $0.37 * *$ & & $0.000 * *$ \\
\hline Proteinuria & $0.42 * *$ & & $0.000 * *$ \\
\hline ANA & $0.60 * *$ & & $0.000 * *$ \\
\hline Anti-dsDNA & $0.50 * *$ & & $0.000 * *$ \\
\hline $\mathrm{C} 3$ & $-0.42 * *$ & & $0.000 * *$ \\
\hline $\mathrm{C} 4$ & $-0.40 * *$ & & $0.000 * *$ \\
\hline
\end{tabular}

Serum IL-18 titers were very high in patients with $(182.91 \pm 11.46,143.21 \pm 10.06 \mathrm{pg} /$ $\mathrm{ml})$ followed by high $(174.75 \pm 1.96,139.68 \pm$ $2.66 \mathrm{pg} / \mathrm{ml})$, moderate $(173.34 \pm 3.26,137.72$ $\pm 2.31 \mathrm{pg} / \mathrm{ml}$ ), and least ones were for mild activity $(170.74 \pm 2.06,133.41 \pm 2.39 \mathrm{pg} / \mathrm{ml})$ for LN patients and SLE patients without LN respectively (Tab. 3).

Table 4: Comparison between IL-18 levels in different classes of SLEDAI score.

\begin{tabular}{|l|l|l|l|l|l|}
\hline Variable & Mild & Moderate & High & Very High & $\mathrm{p}$ \\
\hline Group I(IL-18) & $133.41 \pm 2.39$ & $137.72 \pm 2.31$ & $139.68 \pm 2.66$ & $143.21 \pm 10.06$ & $0.02^{*}$ \\
\hline Group II(IL-18) & $170.74 \pm 2.06$ & $173.34 \pm 3.26$ & $174.75 \pm 1.96$ & $182.91 \pm 11.46$ & $0.001^{* *}$ \\
\hline
\end{tabular}

$* * \mathrm{p}<0.001$ highly significant.

Significant correlation was between serum IL-18 level and arthritis, psychosis and vasculitis without significant correlation with other clinical variables. A positive sig- nificant correlation was between IL-18 and total SLEDAI score, serum creatinine, $24 \mathrm{~h}$ urinary protein, anti-dsDNA abs titer in all patients. A negative significant correlation 
was between IL-18 and C3 \& C4, without significant correlation between serum IL-18 and ESR (Tab. 4).

\section{Discussion}

The present study showed a significance increase in the mean serum IL-18 level of patients with LN than in the SLE patients

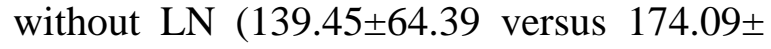
33.19), P <0.001)ng/dl, SLE and LN patients showed significance increase in the mean serum IL-18 level as compared to healthy control $(46.06 \pm 16.42, \mathrm{P}<0.001) \mathrm{ng} / \mathrm{dl}$. The great challenge in diagnosis and monitoring of SLE return to the pathogenic complication and variable clinical symptoms as the skin, renal, central nervous system, glomerulonephritis, dermatitis, seizures vasculitis \& thrombosis were reported (Sui et al, 2013), as well as evidence improves the pathogenic role of cytokines in influences the clinical manifestations in SLE (Yap and Lai, 2010). Also, there was elevation of proinflammatory cytokines of Th1, Th2 (IL-12, IL-17, IL18, IL-4) in the SLE patients (Wong et al, 2002).

The present results complied with the similar previous studies (Shimizu et al, 2012; Mohsen et al, 2013; Chu et al, 2015; Italiani et al, 2018); who found the potent role of IL-18 in pathogenesis of SLE, this result which was supported by the suitable role of the IL-18 in the pathogenesis of SLE particular in LN.

In the present study, no significance difference was between IL-18 level and age or sex, which agreed with Mikita et al. (2011) and Jafari-Nakhjavani et al. (2016).

The present study showed significance relation and correlation between the IL-18 level and (SLEDAI) score $(\mathrm{P}=0.05)$, improved by more evidence that the biomarker levels of $T$ cell activation increased with the disease severity (Medrano et al, 2018).

In the present study, examination of the relationship between serum IL-18 level and SLEDAI score in patients with LN revealed positive and critical correlation observed between IL-18 and SLEDAI $(\mathrm{r}=0.42, \mathrm{P}$
$=0.0001)$. The same result was affirmed by previous studies (Italiani et al, 2018; Lv et al, 2018; Weiss et al, 2018).

By increasing the SLE disease activity and its complications especially $\mathrm{LN}$, the mean level of IL-18 increase. It is noticed that the mean IL-18 level IL-18 level in active SLE patients was significant increase than the mild SLE ones $(133.41 \pm 2.39$ versus $139.68 \pm$ $2.66)$, with $\mathrm{P}<0.02) \mathrm{ng} / \mathrm{dl}$ and $(170.74 \pm 2.06$ versus $182.91 \pm 11.46$ ), with $\mathrm{P}<0.001) \mathrm{ng} / \mathrm{dl}$ for $\mathrm{LN}$ patients.

This advance showed that the IL-18 play an inflammatory role in glomerulonephritis of the LN patients. This result was in concordance and in agreement with another study which demonstrated significant correlation between the plasma IL18 concentration and SLEDAI score in both SLE and LN patients (Chan et al, 2006; Avihingsanon and Hirankarn, 2010; Liu et al, 2012). The IL-18 was found to be correlated with disease activity and kidney damage in both human and animal model as previously recorded by (Weiss et al, 2018).

The present study of relationship between IL-18 level and organs involvement as kidneys, CNS and hematologic disorders, the most predominant clinical variable was malar rash $100 \%$ followed by alopecia $90.32 \%$ then arthritis $74.19 \%$ while least frequent ones were pericarditis and vasculitis followed by purpura was found.

The present results revealed a significant correlation of the mean IL-18 level in patients with (CNS involvement, leukocytopenia, thrombocytopenia, vasculitis, arthritis) $(\mathrm{r}=0.33 \mathrm{p}=0.05, \mathrm{r}=0.29 \mathrm{p}=0.05, \mathrm{r}=-0.31$ $\mathrm{p}=0.002, r=-0.26 \mathrm{p}=0.02, \mathrm{r}=0.34 \mathrm{p}=0.04$ ) respectively was significantly higher in the LN patients than SLE, LN patients and healthy control but, without significant relation between IL-18 level and organs involvement other than the kidney in the SLE patients.

Similarly, the IL-18 level increased in the presence of kidney involvement while other organs involvement did not influence a sig- 
nificant action on IL-18 level (Maczynska $e t$ $a l, 2006)$. Moreover, there was higher IL-18 level in patients with renal involvement (Calvani et al, 2004; Tucci et al, 2008; Andoh et al, 2008). Another study indicated significant correlation between IL-18 level and severity of kidney involvement in SLE patients (Tucci et al, 2008).

In the present study, there was a significant correlation between IL-18 level and anti-dsDNA in all SLE, LN patients, and mean IL-18 level in negative anti-ds DNA patient's significantly less than positive anti-ds DNA ones. This result agreed with $\mathrm{Hu}$ et al. (20100 and Wu et al. (2016).

Furthermore, in the present study, there was significance negative correlation between IL-18 level and serum C3, C4 levels but without significant correlation with ESR. Similarly, serum IL-18 significantly correlated with anti-ds-DNA during active stage in SLE patients, while no significance correlated with other laboratory parameters as ESR, C3 and C4 (Panafidina et al, 2008; Novick et al, 2010).

In the present study, serum creatinine and $24 \mathrm{~h}$ urinary protein significantly correlated with IL-18 level in LN patients. This result proved that level of IL- 18 can reflect the disease activity of LN which supports the other kidney function investigations. The present results agreed with other authors who reported significance correlation between serum creatinine, $24 \mathrm{~h}$ urinary protein and IL-18 level in SLE patients (Tektonidou et al, 2016; Yung and Chan, 2017; McIlroy et al, 2018).

In the present study, the prevalence of Th1 cytokines in the kidney and diffuse proliferative LN encourage kidney injury in SLE patients, which agreed with Kessel et al. (2017). Up-regulation of IL-18 expressing proteinuria led to nephritis irritation (Wu et al, 2016). Generally speaking, the present results proved that the suitability of IL-18 as a very important parameter who play crucial role in the developing SLE and its complications especially LN.

\section{Conclusions}

The patients with SLE are subjected to myriad symptoms, complaints, and inflammatory involvement that can affect the virtually every organ. The commonest pattern is a mixture of constitutional complaints with the skin, musculoskeletal, mild haematologic, and serologic involvement.

The IL-18 proved to have an imperative part in the development and activation of the inflammation in SLE and LN by biological and molecular change, which advance to cellular damage. The serum IL-18 levels can utilized as valuable bio-dia-gnostic marker for observing early kidney damage appearance and foreseeing its recuperation in SLE and lupus nephritis.

\section{References}

Andoh, T, Kishi, H, Motoki, K, Nakanishi, K, Kuraishi, Y, et al, 2008: Protective effect of IL18 on kainate- and IL-1 beta-induced cerebellar ataxia in mice. J. Immunol. 180:2322-8.

Avihingsanon, Y, Hirankarn, N, 2010: Major lupus organ involvement: severe lupus nephritis. Lupus 19:1391-8.

Beker, BM, Corleto, MG, Fieiras, C, Musso, CG, 2018: Novel acute kidney injury biomarkers: Their characteristics, utility and concerns. Int. Urol. Nephrol. 50:705-13.

Bombardier, C, Gladman, DD, Urowitz, MB, Caron, D, Chang, CH, 1992: Derivation of the SLEDAI a disease activity index for lupus patients: The Committee on Prognosis Studies in SLE. Arthrit. Rheum. 35:630-40.

Boraschi, D, Dinarello, CA, 2006: IL-18 in autoimmunity: review. Eur. Cytokine Network 17: 224-52.

Calvani, N, Richards, HB, Tucci, M, Pannarale, G, Silvestris, F, 2004: Up-regulation of IL-18 and predominance of a Th1 immune response is a hallmark of lupus nephritis. Clin. Exp. Immunol. 138:171-8.

Chan, RW, Lai, FM, Li, EK, Tam, LS, Chow, KM, et al, 2006: The effect of immunosuppressive therapy on the messenger RNA expression of target genes in the urinary sedi- ment of patients with active lupus nephritis. Nephrol. Dial. Transplant. 21:1534-40.

Chen, DY, Hsieh, CW, Chen, KS, Chen, YM, Lin, FJ, et al, 2009: Association of interl-eukin18 promoter polymorphisms with WHO patho- 
logical classes and serum IL-18 levels in Chinese patients with lupus nephritis. Lupus 18:2937.

Chu, M, Wong, CK, Cai, Z, Dong, J, Jiao, D, et al, 2015: Elevated expression and pro-inflammatory activity of IL-36 in patients with systemic lupus erythematosus. Molecules 20:19588604.

Dinarello, CA, 2007: Interleukin-18 and the pathogenesis of inflammatory diseases. Sem-in. Nephrol. 27:98-114.

Fessler, BJ, Boumpas, DT, 1995: Severe organ involvement in SLE: Diagnosis and management. Rheum. Dis. Clin. North Am. 21:81-6.

Harrison, OJ, Srinivasan, N, Pott, J, Schiering, C, Krausgruber, T, et al, 2015: Epithelial-derived IL-18 regulates Th17 cell differentiation and Foxp $3^{+}$Treg cell function in the intestine. Mucosal Immunol. 8:1226-36.

Hu, D, Liu, X, Chen, S, Bao, C, 2010: Expressions of IL-18 and its binding protein in peripheral blood leukocytes and kidney tissues of lupus nephritis patients. Clin. Rheumatol. 29: 717-21.

Italiani, P, Manca, ML, Angelotti, F, Melillo, D, Pratesi, F, et al, 2018: IL-1 family cytokines and soluble receptors in systemic lupus erythematosus. Arthrit. Res. Ther. 20:27-32.

Jafari-Nakhjavani, MR, Abedi-Azar, S, Nejati, B, 2016: Correlation of plasma interleukin18 concentration and severity of renal involvement and disease activity in systemic lupus erythematosus. J. Nephropathol. 5:28-33.

Kaplanski, G, 2018: Interleukin-18: Biological properties and role in disease pathogenesis. Immunol. Rev. 281:138-53.

Kessel, C, Lippitz, K, Weinhage, T, Hinze, C, Wittkowski, H, et al, 2017: Proinflammatory cytokine environments can drive interleukin-17 overexpression by $\gamma / \delta \mathrm{t}$ cells in systemic juvenile idiopathic arthritis. Arthrit. Rheumatol. 69:148094.

Levesque, R, 2007: SPSS Programming and Data Management: A Guide for SPSS and SAS Users. $4^{\text {th }}$ Edition SPSS Inc., Chicago, USA. Lit, LC, Wong, CK, Tam, LS, Li, EK, Lam, W, 2006: Raised plasma concentration and exvivo production of inflammatory chemokines in the patients with systemic lupus erythematosus. Ann. Rheum. Dis. 65:209-15.

Liu, X, Bao, C, Hu, D, 2012: Elevated interleukin-18 and skewed Th1:Th2 immune response in lupus nephritis. Rheumatol. Int. 32: 223-9.
Lv, SY, Wu, Q, Liu, JP, Shao, J, Wen, LL, et $a l$, 2018: Levels of interleukin-1 $\beta$, interleukin18 , and tumor necrosis factor- $\alpha$ in cerebrospinal fluid of aneurysmal subarachnoid hemorrhage patients may be predictors of early brain injury and clinical prognosis. World Neurosurg. 111: e362-73.

Maczynska, I, Millo, B, Ratajczak-Stefańs-ka, V, Maleszka, R, Szych, Z, et al, 2006: Proinflammatory cytokine (IL-1beta, IL-6, IL-12, IL18 and TNF-alpha) levels in sera of the patients with subacute cutaneous lupus erythematosus (SCLE). Immunol. Lett. 102:79-82.

McIlroy, DR, Farkas, D, Pan, K, Pickering, J W, Lee, HT, 2018: Combining novel renal injury markers with delta serum creatinine early after cardiac surgery and risk-stratification for serious adverse outcomes: An exploratory analysis. J. Cardiothorac. Vasc. Anesth. 32: 2190-200. Medrano, LM, Garcia-Broncano, P, Berenguer, J, González-García, J, Jiménez-Sousa, M Á, et al, 2018: Elevated liver stiffness is linked to increased biomarkers of inflammation and immune activation in HIV/hepatitis $\mathrm{C}$ virus-coinfected patients. AIDS 32:1095-105.

Mikita, N, Ikeda, T, Ishiguro, M, Furukawa, F, 2011: Recent advances in cytokines in cutaneous and systemic lupus erythematosus. J. Dermatol. 38:839-49.

Mohsen, MA, Abdel Karim, SA, Abbas, T M, Amin, M, 2013: Serum interleukin-18 levels in patients with systemic lupus erythematosus: Relation with disease activity and lupus nephritis. Egypt. Rheumatol. 35:45-51.

Novick, D, Elbirt, D, Miller, G, Dinarello, CA, Rubinstein, M, et al, 2010: High circulating levels of free interleukin-18 in patients with active SLE in the presence of elevated levels of interleukin-18 binding protein. J. Autoimmun. 34:121-6.

Panafidina, TA, Popkova, TV, Alekberova, Z S, Mach, ES, Aleksandrova, EN, Nasonov, E, 2008: Interleukin-18 in systemic lupus erythematosus: link with clinical symptoms and vascular atherosclerosis. Ter. Arkh. 80:41-6.

Park, S, Cheon, S, Cho, D, 2007: The dual effects of interleukin-18 in tumor progression. Ce11. Mol. Immunol. 4:329-35.

Shimizu, C, Fujita, T, Fuke, Y, Ito, K, Satomura, A, Matsumoto, K, Soma, M, 2012: High circulating levels of interleukin-18 binding protein indicate the severity of glomerular involve- 
ment in systemic lupus erythematosus. Mod. Rheumatol. 22:73-9.

Sui, M, Lin, Q, Xu, Z, Han, X, Xie, R, et al, 2013: Simultaneous positivity for anti-DNA, anti-nucleosome and anti-histone antibodies is a marker for more severe lupus nephritis. J. Clin. Immunol. 33:378-87.

Tektonidou, MG, Dasgupta, A, Ward, MM, 2016: Risk of end-stage renal disease in patients with lupus nephritis, 1971-2015: A systematic review and bayesian meta-analysis. Arthrit. Rheumatol. 68:1432-41.

Tucci, M, Quatraro, C, Lombardi, L, Pellegrino, C, Dammacco, F, et al, 2008: Glomerular accumulation of plasmacytoid dendritic cells in active lupus nephritis: role of interleukin-18. Arthrit. Rheum. 58:251-62.

Weiss, ES, Girard-Guyonvarc'h, C, Holzinger, D, de Jesus, AA, Tariq, Z, et al, 2018: Interleukin-18 diagnostically distinguishes and pathogenically promotes human and murine mac- rophage activation syndrome. Blood 131:144255.

Wong, CK, Ho, CY, Li, EK, Tam, LS, Lam, C WK, 2002: Elevated production of interleukin18 is associated with renal disease in patients with systemic lupus erythematosus. Clin. Exp. Immunol. 130:345-51.

Wu, CY, Yang, HY, Yao, TC, Liu, SH, Huang, JL, 2016: Serum IL-18 As Biomarker in Predicting Long-Term Renal Outcome Among Pediatric-Onset Systemic Lupus Erythematosus Patients. Medicine (Baltimore) 95:e5037.

Yap, DYH, Lai, KN, 2010: Cytokines and their roles in the pathogenesis of systemic lupus erythematosus: From basics to recent advances. J. Biomed. Biotechnol. Article ID 365083.

Yung, S, Chan, TM, 2017: Anti-dsDNA antibodies and resident renal cells: Their putative roles in pathogenesis of renal lesions in lupus nephritis. Clin. Immunol. 185:40-50. 